\title{
Etiological Aspects of Nonspecific Ulcerative Colitis
}

\author{
Shaposhnikov Veniamin Ivanovich* \\ Department of Surgical diseases, Vice Rector, Krasnodar, Russia

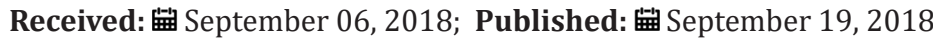 \\ *Corresponding author: Shaposhnikov Veniamin Ivanovich, Department of Surgical diseases, Vice Rector, Krasnodar, Russia
}

\section{Annotation}

The author of the article gives information about the current thinking on the cause of the development of nonspecific ulcerative colitis, with detail reflects the role of domestic factors this pathological process. Special negative role process struggles with weight, when people begin to sharply restrict themselves in eating, turning on sour milk products, exclude the fruits and vegetables. This leads to constipation. Chair happens only once every 2-3 days. To combat it has resorted to klizmam, resulting in dislocation of pathogenic flora from the anus in sigmovidnuju gut and even higher. Dies the normal flora and evolving pathogen that promotes the development of ulcerative process in colon mucosa. Genomodificirovannye products the boat's controllability, immunity, and due to lack of adult lactose dairy products call fermentation adopted food. Gradually creates a pathological complex for the development of the disease. In the prevention of this pathological process man can only help himself.

Keywords: Ulcerative colitis; Domestic factor; Constipation; Enema

\section{Introduction}

Ulcerative colitis (NSU) refers to the number of diffuse chronic recidivating diseases of the colon, which mainly affected its mucous membrane. Some patients of disease are extremely malignant, with the development of segmental necrosis as thin and thick intestines $[1,4,5]$. NSU meets throughout the world. In year 3 to 15 of diagnosed new observations on 100000 of the population, and the incidence of reaches 50-80. Men and women have equally often. The first peak of the delectability of age from 20 years old do40, the second 60-70 years [2-7]. At present, there is no clear information about the etiology and pathogenesis of this disease. It is expected that the development of ulcerative colitis is the breakdown of immunological tolerance to intestinal antigens.

The result is a loss of immunological control of inflammation in the wall of the small and large intestines [2-6]. It is believed that this pathological process normally resists low doses of endogenous gljuko kortiko steroidov (GKS), that in a cage are associated with the specific gljuko kortiko steroidnymi zitoplazmaticakimi receptors. This complex enters the nucleus of the cell and is in contact with DNA elements in the region are gluko kortikoida specific genes. The most often considered to be a hereditary predisposition to the development of autoimmune inflammation in the mucosa of the colon in response to sowing surface microorganisms and viruses, as well as contact the impact food. This opinion is based on the frequent combination of NSU with other autoimmune processes [38].

The discovery of same in colon mucosa of IgG-antibody to epithelial cells and p-ANCA only strengthened the position of the supporters of this hypothesis. Completed studies to determine the ratio of t-lymphocytes in the mucosa of the colon indicate violation agents interactions activated CD4 and CD8 lymphocytes. Normal epithelial cells stimulate the predominantly CD8-T cells. While at NSU they activate CD4 lymphocytes exclusively and is accompanied by IL-2 secretion of lymphokines and stimulation of macrophages in the complement system. Identified and family history of NSU, with first-line relatives fall sick more often than the average population, as well as the risk factors they have clearly seen the use of oral contraceptives, as well as features nutrition and psychosocial problems [3-5].

Literature data suggest an important role of normal intestinal microflora in the adaptation reaction of human organism to the age changing his life [3-8]. In view of these data, the reason becomes clear when you change syndromic pathological development of microflora of the colon. At a young age caused for one reason or another, intestinal dysbiosis is accompanied by diarrhoea, coupled with the brodilnym process. Every fifth patient in this age group are marked with allergic dermatitis, occurring against the backdrop 
of autonomic expressed violations. Dysbacteriosis of the same link with a postponed intestinal infection and long treatment with antibiotics. Performed bacteriological researches in this group of patients indicate expressed growth suppression of Escherichia coli with a simultaneous settlement of the lumen of the colon of conditionally pathogenic microflora (enterobacteria, citrobakterii, Klebsiella, Proteus, fungi kind Candida, gemolizirujushhie strains of Escherichia, etc.).

Individuals have the same maturity (40-59 years), in which there is persistent constipation alternating with diarrhea, bacterial painting Cala proportion of functionally defective (lactosenegative and enzymatically attenuated) strains of e. coli, which occurs against the backdrop of moderate decline bifidumbakterij growth. The same persons over the age of 60 years, suffering persistent constipation, the feces noted a sharp decline in the obligate microflora (Lactobacillus bifidum and Lactobacillus) while increasing the level of conditionally pathogenic microflora [2]. Infections often cause the development and exacerbation of WHEATGRASS, because one way or another damaged mucosa easily kontaminiruetsja pathogenic microflora [3-8]. NSU have detected symptoms of abenteric $20 \%$ of patients. They include Nodular Erythema, gangrenoznaya Pyoderma, inflammatory eye diseases, arthritis, ankylosing spondylitis, respiratory dysfunction, Myositis, Vasculitis, Glomerulonephritis, and other pathological processes outside the walls of the colon guts [3-5].

\section{Purpose and objectives of the study}

Definition of the colon lumen colonization of pathogenic flora in the development of the NSU.

\section{Material and Methods}

Watched 30 patients with NSU, had expressed an enteric (cotton-articulate) symptoms manifestations of the disease, which has resulted in their hospitalization in the casualty department. Only in the course of the survey, they had identified the true cause of the painful condition, i.e. The NSU. All these patients, whose age was from 42 to 68 years, suffered from distorting the artrozami joints of the lower limbs and enclosing spondylitis. Men were $42.2 \%$. Upon admission to the hospital all patients stressed doctors Osteoarticular pathologies and umalchivali about the problems associated with the Act of defecation. Only through the 2-3 days after hospitalization, they began to bring complaints of liquid stool mixed with blood and mucus in the stool.

Frequency defekacij reaches 5-6 times per day. In patients was initially suspected of having perpetuated food toksikonfekcija and diagnostic measures have been made. When you run rectoromanoscopy, attention was drawn to the existence of patients with redness, maceration, and cracks in the perianal region. Endoscopic examination revealed symptoms typical of chronic relapsing, or continuous, relapsing ulcerative colitis. When bacteriological examination of tissue detritus, surface taken from Armenian, discovered microbial Association of Klebsiella, Proteus, gemolizirujushhih esherihi etc. After verification of diagnosis, was assembled a detailed life in the light of identified pathology of colon. It was found that all patients with adolescence suffered from constipation. The Chair was only a day, and sometimes through the 2-3 days.

With age the constipation has become persistent nature and without enemas achieved defecation they failed. Patients often resorted to staging of salt, SOAP, oil and other enemas, which appeared in the left iliac region pain and tenesmus after defecation. In the last year before the hospitalization in the stake appeared mucus and blood veins. For medical assistance. These changes in the Act of urinating associated with frequent taking enemas. Osteoarticular diseases they have begun to develop after 30 years. Colonoscopy revealed only defeat mucous membranes of the colon, with ulcerous defeat was circular in nature. In all patients the disease developed in the background or chronic intoxication, or chronic bacterial infection. No acute surgical pathology allowed story they have conservative treatment and they were transferred to the internal medicine department.

\section{Discussion}

This group of patients in the development of the NSU leading value belongs to the dislocation of the channel anus microbial flora in the lumen of the colon that occurred during staging enemas. Resort to this method of release of the rectum from the faces of patients forced constant constipation experienced with adolescence. The aggravation of the same they have ulcerative colitis on the 2-3 day after the hospital casualty department could explain the sharp changes the nature of power and of psycho-emotional loads. Reduced immunity, allergies and hormonal background contributed to the development of their severe autoimmune process associated with the defeat of the Osteoarticular system. Patients were longterm treatment by a physician [9]. Was not excluded in the future and the development of acute surgical pathology, in the form of necrosis with colon rupture, bleeding, intestinal obstruction, etc. For that reason, they were clinical observation with the surgeon.

\section{Conclusion}

Thus, as a factor contributing to the development of NSU may include deployment of microbial flora of the channel anus in the lumen of the colon that happened when enemas. All 30 patients with this form of chronic inflammatory-jazjaennogo process in thick intestines obvious allergic and autoimmune nature of defeat and osteo-articular apparatus.

\section{References}

1. Vorobev GI, TL Mikhailova, NV Kostenko (2006) Atainable satisfactory results of surgical treatment of ulcerative colitis? Coloproctology 2(16): 34-42. 
2. Golovenko OV, TL Mikhailova, VS Ilyuschenko (2006) Clinical features of ulcerative colitis in patients older. Coloproctology 2(16): 21-24.

3. Zhelnova TI, OG Yakovlev (2003) Kandidozny dysbacteriosis of the intestine. Coloproctology pp. 423-424.

4. VT Ivashkina, FI Komarova, SI Rapoport (2001) Quick start to Gastroenterology 458c.

5. OV Golovenko, Ll Kapuller, TL Mikhailov, VV Veselov, IL Caliph (2005) Place nedifferenciruemogo nonspecific colitis in the spectrum of inflammatory bowel disease. Coloproctology 4(14): 33-34.

6. Sekachev MI (2003) Modern aspects of treatment of nonspecific ulcerative colitis; the results of evidence-based medicine. Consilium medicum p. 18-22.
7. Caliph IL (2006) Principles of treatment of ulcerative colitis (recommendations of the Russian study group on inflammatory bowel disease). Coloproctology 3(17): 31-34.

8. Yakovleva OG, TI Zhelnova, OA Hivinceva (2003) Mikrobiotenoz bowel syndrome in different age groups pp. 439-441.

9. Stack WA, Long RG, Hawkwy CJ (1998) Short-and long-term outcome of patients been pre-treated with cyclosporine for severe acute ulcerative colitis. Aliment Pharmacologic There 12: 973-978.

\section{(c) (?) \\ This work is licensed under Creative \\ Commons Attribution 4.0 License}

To Submit Your Article Click Here:

\section{Submit Article}

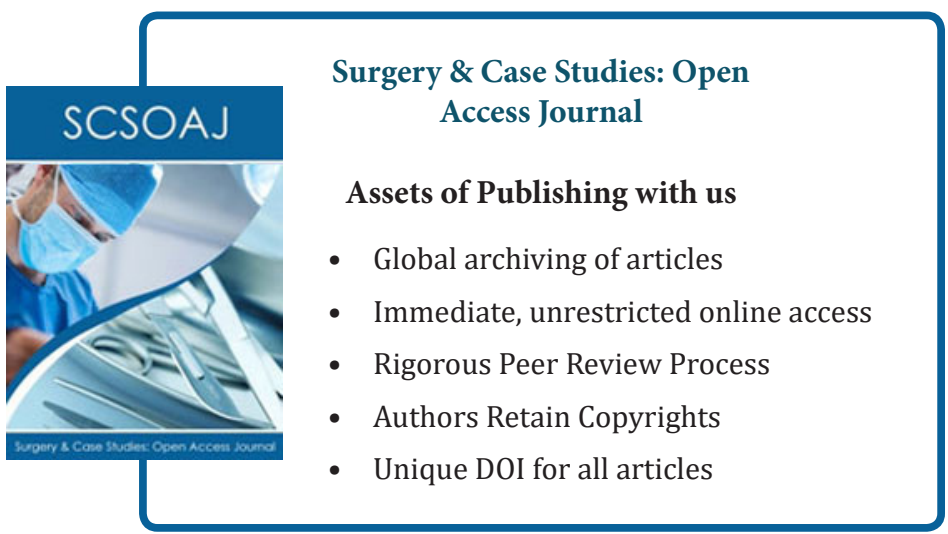

